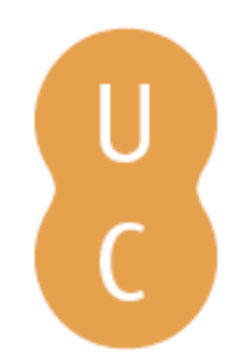

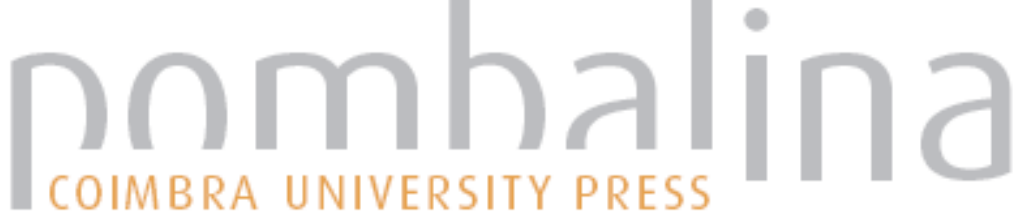

\section{Actores y técnicas de representación en tiempos vicentinos}

Autor(es): Jordá Fabra, Tatiana

Publicado por: Imprensa da Universidade de Coimbra

URL persistente:

URI:http://hdl.handle.net/10316.2/47480

DOI:

DOI:https://doi.org/10.14195/978-989-26-1548-6_18

Accessed : $\quad$ 26-Apr-2023 13:48:37

A navegação consulta e descarregamento dos títulos inseridos nas Bibliotecas Digitais UC Digitalis, UC Pombalina e UC Impactum, pressupõem a aceitação plena e sem reservas dos Termos e Condições de Uso destas Bibliotecas Digitais, disponíveis em https://digitalis.uc.pt/pt-pt/termos.

Conforme exposto nos referidos Termos e Condições de Uso, o descarregamento de títulos de acesso restrito requer uma licença válida de autorização devendo o utilizador aceder ao(s) documento(s) a partir de um endereço de IP da instituição detentora da supramencionada licença.

Ao utilizador é apenas permitido o descarregamento para uso pessoal, pelo que o emprego do(s) título(s) descarregado(s) para outro fim, designadamente comercial, carece de autorização do respetivo autor ou editor da obra.

Na medida em que todas as obras da UC Digitalis se encontram protegidas pelo Código do Direito de Autor e Direitos Conexos e demais legislação aplicável, toda a cópia, parcial ou total, deste documento, nos casos em que é legalmente admitida, deverá conter ou fazer-se acompanhar por este aviso. 

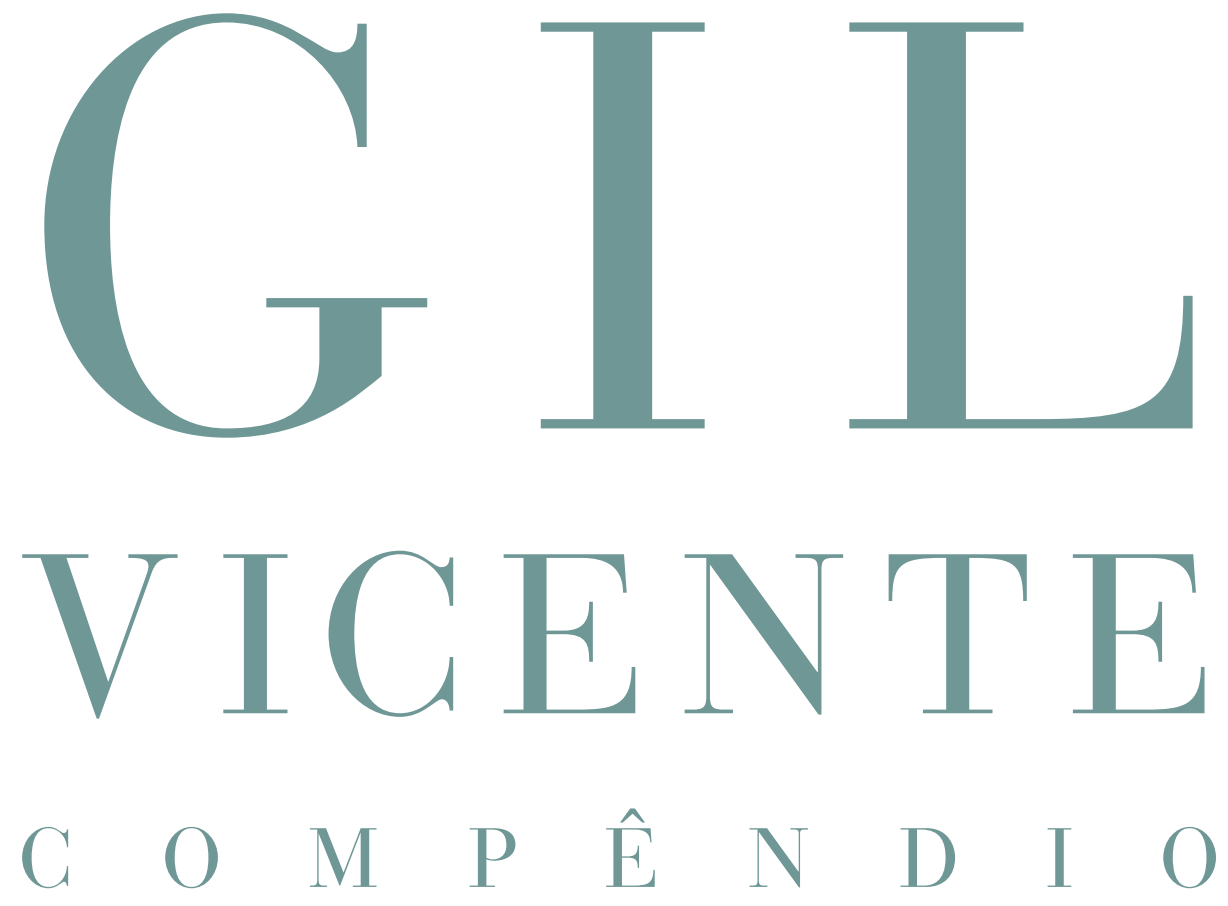

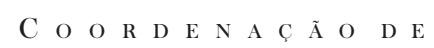

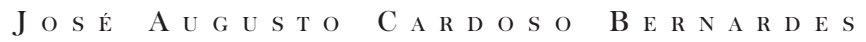

E J O S É C A M Õ E S

CoimbraCompanions

IVPRENSA DA UNIVERSIDADE DE COIMBRA

COIMBRA UNIVERSITY PRESS

IMPRENSA NACIONAL 


\section{XVIII}

\section{Actores y técnicas de representación en tiempos vicentinos}

Tatiana Jordá Fabra

Universitat de ValènCIA 
(Página deixada propositadamente em branco) 


\section{ESTUdios Y LÍNEAS DE INVESTIGACIÓN SOBRE LOS PRIMEROS REPRESENTANTES}

El estudio del actor y de su técnica de representación resulta del máximo interés para recuperar un arte de frágil memoria que, formando parte del patrimonio cultural, es asimismo una herramienta de reconstrucción de las poliédricas prácticas escénicas del Quinientos peninsular. El estudio de estas prácticas se ha centrado hasta el momento, como es lógico, en el estatuto textual de los diversos dramaturgos; pero otros campos de conocimiento, como el de la interpretación o aquellos a quienes fue confiada esta, ofrecen una gran fragmentación, cuando no una práctica escasez documental al ser el del actor, entretenedor o intérprete un arte que, a caballo entre la Edad Media y el Renacimiento, no ofrecía tratados o poéticas explícitas.

No obstante, contamos con algunos interesantes trabajos, sobre todo procedentes de la filología italiana, que han tratado de comprender el mundo del actor medieval. Así lo hace Luigi Allegri en su "Aproximación a una definición del actor medieval» ${ }^{1}$ y que, incluso, nos ofrece un breve recorrido pedagógico por el oficio - incluyendo el Quinientos - en L'arte e il mestiere. L'attore teatrale dall'antichità ad oggi ${ }^{2}$. Pese a que el libro se

1 En Evangelina Rodríguez Cuadros (ed.), Cultura y representación en la Edad Media. Actas del Seminario celebrado con motivo del II Festival de Teatre i Música Medieval d'Elx (Octubre-Noviembre de 1992), Alicante, Instituto de Cultura Juan Gilalbert, 1995, pp. 125-136.

2 Roma, Carocci editore, 2005 (Ed. ut. 2012). 
centra en los cómicos italianos, es un precedente claro de la utilidad de esta senda y, además, sus bases teóricas son extrapolables en cierto modo al territorio peninsular. En la misma línea que Allegri, encontramos también los trabajos de Luís Quirante Santacruz, quien dedicó gran parte de sus reflexiones al teatro medieval, tanto en lengua castellana como en catalana 3 .

El estado de la cuestión es, pues, mínimo si lo comparamos con otras épocas, aunque se percibe un interés creciente por ello. Hasta el momento, algunos especialistas de la filología hispánica se han mostrado atraídos por la sociología del comediante y la puesta en escena durante el siglo XVI, si bien la técnica de representación es todavía un territorio muy poco explorado. En los años 60, se publicó el trabajo pionero de Jean Duvignaud ${ }^{4}$, que abrió la senda para que otros autores como Manuel Sito Alba, casi dos décadas después, llamaran la atención hacia los representantes de un teatro que ya exigía algo más que gesto y movimiento ${ }^{5}$. Por su parte, Maria Grazia Profeti ha realizado también investigaciones de gran utilidad para la comprensión de la génesis y desarrollo de esta generación preprofesional, si bien centra su atención en la relación del actor con el resto de elementos del hecho teatral: público, escenario, autor y circunstancias. Su Introduzzione allo studio del teatro spagnolo ${ }^{6}$ es, sin duda, una obra de referencia en la comprensión del nacimiento de la conciencia de profesionalidad en el teatro peninsular. También lo son a este respecto los estudios de José Luís Canet Vallés, quien ha dedicado algunos de sus trabajos a reflexionar sobre la progresiva profesionalización de aquellos primeros representantes y, más concretamente, de la generación de los

3 Cf. Quirante Santacruz, "La ciudad en el templo: La consueta de Santa Ágata", en Rodríguez Cuadros (ed.): Cultura y representación..., pp. 171-189; "Sobre el actor en la Baja Edad Media", en Evangelina Rodríguez (coord.): Del oficio al mito: el actor en sus documentos, vol. I, Valencia, Universitat de València, 1997, pp. 91-120.

4 El actor. Bosquejo de una sociología del comediante, Madrid, Taurus, 1966.

5 "El teatro en el siglo xvi (desde finales de la Edad Media a comienzos del siglo XVII)", en J. M. ${ }^{a}$ Díez Borque (ed.), Historia del teatro en España, Madrid, Taurus, 1983, pp. 155-471. Más concretamente pone como ejemplo la Farsa o cuasicomedia de Prabos y Antona de Lucas Fernández, p. 379.

6 María Grazia Profeti, Florencia, La casa Usher, 1994. Sigue esta línea en otro artículo indispensable: "La profesionalidad del actor: fiestas palaciegas y fiestas públicas», en VV. AA., Los albores del teatro español, Actas de las XVII Jornadas de teatro Clásico, Almagro, julio de 1994, Almagro, Festival de Almagro-Universidad de Castilla la Mancha, 1995, pp. 69-88. 
autores-actores ${ }^{7}$. Finalmente, cabe mencionar los estudios de Carmen Sanz Ayán y Bernardo J. García García, autores que han indagado sobre el ámbito paraprofesional de los autores donde se produce el paso desde un estadio meramente artesanal o gremial al profesional surgiendo así las primeras compañías; sobre el oficio de representar — tanto en su aspecto sociológico y organizativo, como económico y legal - de los primeros cómicos en el Madrid del siglo XVI y el carácter de las actividades teatrales en las que participaban ${ }^{8}$.

Más recientemente, Teresa Ferrer ha profundizado en el lugar social del comediante de la época o en el funcionamiento de las compañías. Tiene, no obstante, algunos estudios en los que sí especula sobre qué consistía la representación. Por ejemplo, en su capítulo incluido en la Historia del teatro español dirigida por Huerta Calvo, Ferrer da cuenta del lugar ocupado en la Corte por estos primeros actores, así como de las circunstancias y espacios de representación. Señala casos puntuales de Lucas Fernández o Juan del Encina, en los cuales va operándose un cambio en la relación entre actor/autor y público, al mismo tiempo que maduraba paulatinamente la técnica de representación?. Así resume su punto de vista sobre el estadio de la representación en esta época:

En España durante las primeras tres décadas del siglo los espacios de representación cortesana aparecen monopolizados por las églogas pastoriles, que constituyen básicamente teatro de la palabra, con poca elaboración de la parte material de la representación (limitada fundamentalmente al vestuario y al atrezzo pastoril). ${ }^{10}$

En páginas posteriores, vincula las prácticas cortesanas con el fasto y las máscaras originadas en el momo medieval, dedicando el resto del estudio al

7 Cf. «El nacimiento de una nueva profesión: los autores-representantes (1540-1560)», Edad de Oro, vol. 16, 1997, pp. 109-120; "Algunas puntualizaciones sobre los orígenes del teatro popular en España: el caso de Lope de Rueda", en Teresa Ferrer y Manuel Diago (coords.), Comedias y comediantes: estudios sobre el teatro clásico español: actas del congreso internacional sobre teatro y prácticas escénicas en los siglos XVI y XVII, Valencia, Universitat de València, 1991, pp. 79-90.

8 Teatros y comediantes en el Madrid de Felipe II, Madrid, Editorial Complutense, 2000.

9 Huerta Calvo, op. cit., p. 9.

10 Idem, ibidem. 
proceso de profesionalización del actor y de las primeras compañías ${ }^{11}$. De hecho, es esta época y sus protagonistas quienes acaparan los estudios posteriores de Ferrer, sobre todo en su Diccionario Biográfico de Actores del Teatro Clásico Español (DICAT): ${ }^{12}$ una enorme catalogación de la documentación generada por la actividad teatral a partir de la década de 1540, lo que lo convierte en una herramienta de gran ayuda para conocer el funcionamiento del teatro como negocio, la historia y articulación de las compañías, acercándonos de este modo al oficio de ese actor ya profesional.

En cuanto a las monografías sobre el actor, debe mencionarse el libro - más de divulgación que de investigación — de Josef Oehrlein, El actor en el teatro español del Siglo de Oro ${ }^{13}$, dedicando sus esfuerzos a explicar la vida cotidiana del oficio del actor de la escena siglodorista, incidiendo de nuevo, sobre todo, en los aspectos sociológicos de la profesión. Eso sí, la imagen del actor plasmada en alguno de sus estudios como la de un "perito en el rito de la representación» que cumple "la misma función que el sacerdote que celebra el misterio eucarístico» ${ }^{14}$ rodean al actor de un aura innecesariamente mística y poco ajustada a la documentación real.

Si buscamos trabajos enfocados totalmente en la técnica del representante, sólo encontramos precedentes claros en el Barroco, periodo en el que culmina la profesionalización y técnica actoral alumbrada en el siglo XVI. Es todavía indispensable el breve estudio de Juan Manuel Rozas "Sobre la técnica del actor barroco», que abría un fructífero camino con este tipo de afirmaciones:

Podemos entender un soneto culterano o un capítulo conceptista. Es un problema casi exclusivo de sabiduría filológica. Pero ante un texto de la comedia nueva nos faltan dos dimensiones imposibles de reconstruir: el ademán

11 También son interesantes otros trabajos dedicados al teatro cortesano de la misma autora como La práctica escénica cortesana: de la época del Emperador a la de Felipe III, Londres, Tamesis Books-I.V.E.I., 1991, y Nobleza y espectáculo teatral (1535-1622). Estudio y documentos, Valencia, Universitat de València, UNED, Universidad de Sevilla, 1993.

12 Kassel, Reichenberger, Colección Teatro del Siglo de Oro. Biografías y Catálogos, 2008.

13 Publicado en Madrid, Castalia, 1993.

14 "El actor en el Siglo de Oro: imagen de la profesión y reputación social», en José M. ${ }^{a}$ Díez Borque (ed.), Actor y técnica de representación del teatro clásico español, Londres, Támesis Books, 1989, p. 25. 
XVIII. ACTORES Y TÉCNICAS DE REPRESENTACIÓN EN TIEMPOS VICENTINOS

y la entonación. Nos bastarían unas pocas "fotos» - aunque fijas - , un trozo de película - aunque fuese muda - , un fragmento de grabación - aunque sin imagen - , para iluminarnos de forma insospechada. Hemos de pensar lo cerca que estará el teatro del siglo xx para los hombres de siglos futuros ante la posesión de obras y obras grabadas — imagen y sonido - que les dejamos. ${ }^{15}$

Casi una década después, la crítica filológica mantenía las mismas inquietudes que había puesto sobre la mesa Rozas; y prueba de ello fue el libro coordinado por José M. ${ }^{a}$ Díez Borque Actor y técnica de representación del teatro clásico español ya citado anteriormente. En él se reunieron interesantes ensayos sobre el oficio y técnicas de representación del actor barroco, entre los que destacan el de Víctor Dixon «Manuel Vallejo: un actor se prepara: un comediante del Siglo de Oro ante un texto (El castigo sin venganza)» ${ }^{16} \mathrm{y}$, sobre todo, las páginas a cargo de Evangelina Rodríguez bajo el epígrafe «Registros y modos de representación en el actor barroco: datos para una teoría fragmentaria.» ${ }^{17}$ Destacamos este último porque, además de centrarse en la técnica actoral alejándose de la sociología del comediante o de la pura teoría sobre el hecho teatral, supone el anticipo del libro posterior La técnica del actor español en el Barroco. Hipótesis y documentos $^{18}$. En él se elaboran hipótesis concretas acerca del modo o modos de representar del actor del siglo XVII y se abre una nueva prospectiva metodológica para el estudio científico de un "arte» o técnica que ya existía aunque no se hubiera conceptualizado teóricamente.

No obstante, otros trabajos de Rodríguez Cuadros exploran estos senderos, entre los que cabe subrayar el realizado junto a Luís Quirante y Josep Lluís Sirera, donde ya quisieron acercarse al drama desde la Edad Media hasta el Siglo de Oro desde un punto de vista más teatral y menos

15 En Anuario de estudios filológicos, vol. 3, 1980, p. 191.

16 En Díez Borque, Actor y técnica..., op. cit.,1989, pp. 55-74.

17 Idem, ibidem, pp. 35-54.

18 Evangelina Rodríguez Cuadros, Madrid, Castalia, 1998. Con anterioridad a este libro, la autora ya había mostrado su interés con la coordinación del libro Del oficio al mito: el actor..., citado en la nota 3 . 
literario $^{19}$. Posteriormente, el propio Sirera se concentraba más en los actores con su artículo «Espectáculo y representación. Los actores. El público. Estado de la cuestión» ${ }^{20}$.

Pero es, sin duda, Alfredo Hermenegildo ${ }^{21}$ quien más se ha ocupado de buscar la teatralidad encerrada en las palabras de algunos de los autores castellanos de los primeros compases del Quinientos. Y, aunque no se centra en la caracterización de la técnica actoral como Rodríguez Cuadros en el caso del actor barroco, sí cuenta con valiosísimas investigaciones en las que demuestra la existencia de lo que él llama "virtualidad escénica».

19 Nos referimos al casi podríamos llamar manual Pràctiques escèniques de l'edat mitjana als segles d'or, Valencia, Universitat de València, Colección Educación. Materiales, 24, 1999. V. también de Rodríguez Cuadros: "Gesto, movimiento, palabra: el actor en el entremés del Siglo de Oro", Los géneros menores en el teatro español del Siglo de Oro (Jornadas de Almagro, 1987), ed. de L. García Lorenzo, Madrid, Ministerio de Cultura, Instituto Nacional de las Artes Escénicas y de la Música, 1988, pp. 47-93; "El actor en el Siglo de Oro español: Materiales para una historia posible», A Scociety on Stage. Essays on Spanish Golden Age Drama, New Orleans, University Press of the South, 1998, pp. 203-221; "El actor y las técnicas de interpretación", en Javier Huerta Calvo (dir.), Historia del Teatro Español. I. De la Edad Media a los Siglos de Oro, Madrid, Gredos, 2003, t. I, pp. 655-676; "Un cuerpo sobre el tablado: el trabajo del actor en el teatro clásico", en VV. AA., La geometría de las emociones. Arte, pedagogía y teatro en la ESAD de Valencia 2002-2004, Valencia, Publicaciones de la ESAD, 2005, pp. 101-114; "Gente de placer en el Siglo de Oro: de la enciclopedia arqueológica a la ciencia de representar», en Renovación en el Siglo de Oro: repertorio e instrumentos de investigación. Cuadernos de Teatro Clásico, núm. 29, pp. 261-296. "Arte sin arte, oficio con oficio: el descuido cuidadoso y el actor barroco", en El libro vivo que es el teatro. Canon, actor y palabra en el Siglo de Oro, Madrid, Cátedra, 2012, pp. 143-194.

20 En J. Canavaggio (ed.), La comedia, Madrid, Casa de Velázquez, 1995, pp. 115-30.

21 "Mover las palabras: Encina y la teatralización progresiva", en Irene Pardo Molina, Luz Ruiz Martínez y Antonio Serrano (eds.), En torno al teatro del Siglo de Oro. XIV Jornadas del Siglo de Oro (7 al 16 de marzo de 1997), Almería, Instituto de Estudios Almerienses-Diputación de Almería, 1999, pp. 19-41; "Acercamiento al estudio de las didascalias del teatro castellano primitivo: Lucas Fernández", en Actas del VIII Congreso de la Asociación Internacional de Hispanistas (22-27 de agosto, 1983), Madrid. Istmo, 1986, t. I, pp. 709-727; "Los signos de la representación: la comedia Medora de Lope de Rueda", en José M. ${ }^{a}$ Ruano de la Haza (ed.), El mundo del teatro español en su siglo de oro, Ottawa, Dovehouse Editions Inc., 1988, pp. 161-176; "Los signos condicionantes de la representación: el bloque didascálico", en Luis T. González del Valle y Julio Baena (eds.), Critical Essays on the Literatures of Spain and Spanish America, Ed. Boulder, Colorado, Society of Spanish and Spanish-American Studies, 1991, pp. 121-131; "El arte celestinesco y las marcas de teatralidad», en Incipit, Buenos Aires, Seminario de Edición y Crítica Textual, IX, 1991, pp. 127-151; "La representación imaginada: estrategias textuales en la literatura dramática del siglo xvi (el caso de la Numancia de Cervantes"), en Francis Cerdan (ed.), Hommage à Roben Jammes, Tolouse, Presses Universitaires - Le Mirail, 1994, pp. 531-543; "Procedimientos de teatralización: la Nise lastimosa de Jerónimo Bermúdez", en José M. ${ }^{a}$ Ruano de la Haza, La puesta en escena del teatro clásico, Cuadernos de Teatro Clásico, 8, 1995, pp. 15-36. 
En ellos realiza un exhaustivo trabajo de análisis de las didascalias de las églogas de Encina y de alguna de las obras de Lucas Fernández, que tienen una gran relevancia y son perfectamente aplicables al teatro vicentino. También son destacables sus interesantes trabajos sobre el lugar del actor y su relación con el personaje y el público para comprender quién es quién dentro de la escena cortesana de principios de siglo. Nos interesa muy especialmente Texto, escena y público en el Quinientos español: modelos encadenados ${ }^{22}$, en el cual realiza un estudio global de los autores que escribieron en castellano durante esta época y sobre la naturaleza de sus prácticas, independientemente de sus orígenes o del desarrollo de las mismas. Si bien hay un pequeño apartado centrado en los actores como uno de los elementos de la representación, nos interesa sobre todo esa mirada global que articula el estudio así como sus ideas respecto a las prácticas escénicas que integraron a dichos actores. Finalmente, el mismo Hermenegildo tiene también otros trabajos que se adentran en las diferentes figuras y personajes de las obras de los autores de la llamada generación de los Reyes Católicos a la que pertenece Gil Vicente. Estudios interesantes que tratan de encontrar las claves de la creación de personajes aunque en su mayoría se centren en el aspecto literario ${ }^{23}$.

Ya desde la filología lusitana, son menos los estudios sobre la puesta en escena y los actores, aunque sí interesa cada vez más el teatro en general y ya existen encomiables esfuerzos por recuperarlo ${ }^{24}$. José Camões se muestra contrario a la identificación del teatro de Gil Vicente como un mero teatro de palabras, un teatro sin acción. Afirma que hay interpretación, dirección de actores y que, en definitiva, es un ejercicio más maduro y complejo de lo que gran parte de la crítica ha establecido. Finalmente, también han trabajado en la virtualidad escénica de las obras vicentinas

22 Alfredo Hermenegildo, Trois-Rivières, Anejos de TeaPal, 2013. Edición al cuidado de Ricardo Serrano Deza

23 Nos referimos a trabajos como «Personaje y teatralidad: La experiencia de Juan del Encina en la Égloga de Cristino y Febea", en Felipe B. Pedraza Jiménez y Rafael González Cañal (eds.), Los albores del teatro español, Almagro, Universidad de Castilla-La ManchaFestival de Almagro, 1995, pp. 91-113.

24 Cabe destacar, entre otros, los de Laurence Keates o Maria João Brilhante, que otorgan especial relevancia a la puesta en escena. 
Stanislav Zimic ${ }^{25}$ y el investigador sueco Leif Sletsjöe, de quien nos interesan particularmente sus notas sobre el potencial escenográfico de las obras de Gil Vicente ${ }^{26}$. En ellas realiza una atrevida clasificación - muy inspiradora - según el grado de virtualidad teatral de las piezas, además, demuestra que el trabajo del dramaturgo portugués puede ser considerado también desde el punto de vista escenográfico, además del textual. Si bien es cierto que se trata de un examen superficial, es interesante como instrumento de contraste con nuestras propias hipótesis, así como un ejemplo del cuestionario al que podrían someterse las composiciones del autor portugués.

Por otra parte, hay también una original línea de investigación que pone en contacto los autos de Gil Vicente con técnicas contemporáneas de escenificación. Y el hecho es que nos resulta interesante porque, en el caso de los estudios de Heloísa Machado ${ }^{27}$, se conecta al actor moderno con los personajes del mestre Gil, cuyo punto de vista profesional encuentra en estas figuras un punto de conexión con los actores que les dieron vida. Esta línea de trabajo demuestra el cambio que está operándose en la intelectualidad portuguesa, que mira cada vez más hacia esta producción con una lente más teatral. Claro ejemplo de ello son los artículos que hacen referencia a los mecanismos de dramatización utilizados por Gil Vicente para llevar a la escena las novelas de caballería. Entre ellos, destacan los trabajos de Aníbal Pinto de Castro $^{28}$ y M. ${ }^{a}$ Rosa Álvarez Sellers ${ }^{29}$.

Por último, también hallamos otra vía de estudio abierta y recorrida por algunos críticos, y que pone en contacto, desde diversos puntos de vista, al dramaturgo portugués con sus coetáneos españoles. Así, destacan los trabajos

25 Ensayos y notas sobre el teatro de Gil Vicente, Madrid: Iberoamericana/Frankfurt am Mein: Vervuert, 2003.

26 O elemento cénico em Gil Vicente, Suécia-Lisboa, Instituto Ibero-Americano Estemburgo, 1965.

27 "Gil Vicente: A linguagem dos autos e uma técnica contemporânea de sua encenação", en Gil Vicente 500 Anos depois - Actas do Congreso Internacional realizado pelo Centro de Estudos de Teatro da Faculdade de Letras da Universidade de Lisboa, Lisboa, Imprensa NacionalCasa da Moeda, 2003, pp. 375-383.

28 Cf. "As dramatizaçõoes vicentinas da novela de cavalaria», en Gil Vicente 500 Anos depois..., op. cit., pp. 13-30.

29 Cf. "Da novela de cavaleria à comédia renascentista: Don Duardos e Amadís de Gaula de Gil Vicente», Limite: Revista de Estudios Portugueses y de la Lusofonia, n. ${ }^{\circ}$ 1, 2007, pp. 159-173. 
de Manuel Calderón ${ }^{30}$ o Maria Idalina Resina Rodrigues. Esta última realiza todo un ejercicio de lucidez en su "Gil Vicente e a festa ibérica» ${ }^{31}$, en el que establece el nacimiento y desarrollo de algunos personajes de Vicente.

Hay quien ha reclamado un estudio pormenorizado de la técnica de los actores, como en el caso de José Alberto Ferreira, que habla sobre la importancia del rastreo de la técnica del actor a través del texto en su artículo "Do fazer da figura em Gil Vicente.» ${ }^{32}$ Esta línea — inspirada en los citados estudios de Rodríguez Cuadros y de Hermenegildo - es la que seguimos en Hacia el actor profesional en el teatro peninsular renacentista ${ }^{33}$ y que presentamos aquí como un nuevo acercamiento a las prácticas escénicas vicentinas desde la técnica interpretativa de sus representantes.

\section{EL ACTOR Y LA PALABRA:}

\section{Un NUEVo CAMino hacia El TEATRO DE Gil ViCEnTE}

Esbozado, con sus luces y sombras, el status questionis, creemos interesante analizar y catalogar el léxico específicamente teatral y los elementos de la práctica escénica capaces de determinar la técnica actoral en las obras de Gil Vicente. Se enmarca así esta propuesta en la senda de los historiadores y críticos del teatro citados que reconocen la existencia de un representante y de unas prácticas escénicas no solo textuales. Esta es una vía bastante inédita porque durante mucho tiempo se ha negado la virtualidad escénica de muchas de las obras del dramaturgo luso, expresando que se trata de un teatro para ser recitado o leído. En nuestra opinión, este teatro de palabras, es también un teatro hecho de acciones y gestos.

El rastreo y análisis semántico de las obras se propone poner al descubierto las marcas de teatralidad que han quedado en las didascalias internas

30 "Temas y formas del teatro castellano de Gil Vicente», en Gil Vicente 500 Anos depois..., op. cit., pp. 131-147.

31 Cf. Maria Idalina Resina Rodrigues, en Gil Vicente 500 Anos depois..., op. cit., pp. $149-180$.

32 En Gil Vicente 500 Anos depois..., op. cit., pp. 499-509.

33 Tatiana Jordá Fabra, Tesis doctoral, Universitat de València, Valencia, febrero de 2016. 
y externas, implícitas y explícitas, revelando los signos de una tejné de la representación escénica siquiera en sus formas más incipientes. Para el análisis del mismo, es interesante acudir a los diccionarios, obras literarias y críticas más próximos a la época, que nos ayuden a determinar si tales palabras o locuciones se insertaban en contextos cercanos al espectáculo y, concretamente, al arte de sus protagonistas. He aquí una muestra de la lexicografía de mayor interés para tales fines: Tesoro de la lengua castellana de Sebastián de Covarrubias (1611); Diccionario de autoridades (1726-1739); Diccionario Castellano y Portuguez para facilitar a los castellanos el uso del Vocabulario Portuguez de Raphael Bluteau (1721); Vocabulário portuguez e latino también de Raphael Bluteau (1712-1728) y el Thesouro da lingua portugueza de Bento Pereira (1697).

Las obras de Gil Vicente constituyen un objeto amplio y diverso, que abarca desde las primeras representaciones producidas en la península - junto a las de sus coetáneos castellanos Encina y Fernández — hasta las inmediatamente anteriores a la profesionalización del oficio. La metodología intenta responder al corpus al que nos enfrentamos, y por ello creemos pertinente utilizar todas aquellas fuentes que puedan suministrarnos información sobre la técnica. En este sentido, las acotaciones se revelan como un documento clave para entender la llegada del teatro a un estatuto plenamente profesional en el momento en que empiezan a fluir las compañías, ya que puede permitir el trazado de las líneas o parámetros en los cuales se movió ese primer representante anterior a la profesionalización del oficio prácticamente en la década de 1540. Esta cronología viene dada por el surgimiento de las primeras compañías y simbolizarse en un documento muy significativo datado en 1539:

En la representación de comedias que en Castilla llaman farsas, nunca desde la creación del mundo se representaron con tanta agudeza e industria como agora, porque viven seis hombres asalariados por la Iglesia de Toledo, de los cuales son capitanes dos que se llaman los Correas, que en la representación contrahazen todos los descuidos e avisos de los hombres, como si la Naturaleza, nuestra universal madre, los representase allí. Estoy tan admirado de lo ver, que si alguno me pudiera pintar con 
XVIII. ACTORES Y TÉCNICAS DE REPRESENTACIÓN EN TIEMPOS VICENTINOS

palabras lo mucho que en ellos en este caso son, gastara yo grandes sumas de dinero. ${ }^{34}$

Si hablar de técnica de actuación es enunciar que se realiza una acción con valor estético a cambio de un salario, el texto de Villalón no deja margen a la duda de que ese concepto ya existe - con bastante nitidez - a finales de los años 30, en la cual estrena Vicente sus últimas piezas.

Nuestra propuesta de investigación sugiere la lectura de las obras atendiendo a su cronología así como a su clasificación genérica, de modo que puedan aislarse los distintos materiales y las diferentes tradiciones actorales que confluyeron en estas prácticas escénicas. De este modo, las moralidades, farsas y comedias vicentinas deberían someterse a un análisis exhaustivo y comparativo a nivel cronológico pero también temático siempre desde el prisma de la actuación.

Gil Vicente, al igual que los autores castellanos del momento, produce un teatro de circunstancias en estrecha relación con el poder, en el cual se establece un diálogo con un público que está presente también en muchas de sus representaciones. La relación del actor con el espacio y el público cambiará atendiendo a la temática de la obra, rompiéndose en mayor o menor medida las barreras de separación entre autor-actor y público. Podría decirse que la adaptación y gran habilidad comunicativa es la más patente de todas las virtudes de las prácticas escénicas del primer Renacimiento. Las diversas circunstancias de celebración y autocelebración cortesanas originan escenas y escenarios distintos $y$, por tanto, diversas maneras de actuación. Los materiales culturales a disposición de los representantes posibilitan la representación de cualquier personaje en cualquier espacio: la iconografía, los ritos religiosos, la retórica y la oratoria, las tradiciones literarias, interpretativas y espectaculares, serán las sustancias y fuentes de las cuales beben estos primeros actores.

Hasta el momento, el análisis de algunas de sus obras nos ha permitido hallar numerosos indicios o huellas de la técnica actoral, que van en claro

34 Apud M. Serrano y Sanz (ed.), Cristobal de Villalón. Ingeniosa comparación entre lo antiguo y lo presente, Madrid, Sociedad de Bibliófilos Españoles, 1898, pp. 178-180. 
aumento con el paso de los años y sugieren una evolución palpable de la misma. Cada género conoce diversas formas de representación y, además, vive una evolución interna apreciable no sólo en una creciente complicación escenográfica, sino en la mayor tipificación de los personajes.

Un testimonio significativo de los modos actorales en las obras de temática religiosa lo hallamos en el Auto Pastoril Castelhano. Esta égloga presenta acotaciones que nos indican que los pastores actúan con revelencia y deboción, ofreciéndonos una representación con apego al ritual y cercana a la máscara establecida por Encina y Fernández. La tradición litúrgica también habría dejado huella en el resto de acciones de los pastores y por eso no solo debían acercarse con hemencia y devoción a contemplar al niño, sino que también tenían que cumplir con el acto de oferecer sus presentes, eso sí, com muy chapada hemencia y con revelencia ("Ora vosotros qué hacéis? / Con muy chapada hemencia / y con vuestra revellencia / dalde deso que traéis» vv. 322-325). Esa "hemencia» no es más que la deformación de vehemencia recogida por Bluteau como sinónimo de "Ardor do animo. Paixão, fervor.»35 También resulta descriptiva la siguiente acotación explícita, si bien, seguramente, fue añadida por el editor: "Com tangeres e bailos oferecem e à despedida cantam esta chançoneta." Los tangeres y bailes son acciones propias de los pastores, mientras que oferecer hace referencia al rito de la ofrenda.

Los juegos y la música forman parte de la máscara del Pastor, como aficiones preferidas, además de la comida y la bebida. En este auto Vicente muestra, por ejemplo, una imagen bastante clara del juego del abejón, inscribiendo en los versos las didascalias implícitas oportunas para los representantes. Los pastores debían colocarse en determinadas posiciones y hacer gestos muy precisos que coinciden plenamente con la descripción del juego tal y como aparece en el Diccionario de Autoridades. Se busca la risa del cortesano por la simpleza de los juegos de los rústicos y también por sus propias acciones, que habrían de resultar graciosas porque uno de ellos terminaba recibiendo una porrada, como también demuestra la didascalia «dite una de mal mes». Dice Bluteau que porrada es una «Pancada dada

35 Vocabulario de synonimos, e phrases portuguezas, Supplemento ao Vocabulário Portuguez e Latino, II, Lisboa, Patriarcal Officina de Musica, 1728, 57-424. Ed. On line Corpus Lexicográfico do Português, Universidade de Lisboa (http://clp.dlc.ua.pt/Corpus/RafaelBluteau_Sinonimos.aspx). 
com porra, ou cachaporra, ou (como dizem outros) cachamorra». Este tipo de golpes acabará convirtiéndose en un elemento cómico muy importante de la dramaturgia posterior a Gil Vicente, sobre todo en los entremeses.

Pero hay también otro tipo de acotaciones que hacen clara referencia a la técnica vocal y gestual. En varios momentos de la pieza los pastores se llaman entre ellos de longe (de lejos), lo cual puede suponer dos cosas: que el pastor que va a realizar dicha acción ha de estar fuera del escenario y gritar de modo que se le escuche desde dentro; o bien que este tiene que modular su voz para conseguir el efecto de que el público lo escuche como si estuviera más lejos. En ambos casos se entrevé el deseo de conseguir un mayor grado de verismo y otorgar cierta profundidad a la escena, marcando un espacio de representación cuyas fronteras se encuentran poco delimitadas - la mayor parte de la crítica considera que estas primeras piezas se representaban a ras del suelo - pero nosotros nos inclinamos por una fusión de ambas, ya que, si nos remitimos a la definición de lejos ${ }^{36}$ dada por Covarrubias, vemos que se hace una referencia muy útil para entender que ese salir afuera tal vez supusiese, como en la pintura de la época, únicamente apartarse de la figura central. Se buscaba el naturalismo y tal vez los actores modularan también su voz para otorgar más realismo a la acción.

La Barca do Inferno presenta, como alegoría, un tono alejado de la rusticidad de las églogas y se impregna de cierto hieratismo, un lenguaje escénico basado en la iconografía y una notable caracterización lingüística de los personajes. No obstante, la vivacidad de las palabras de la vasta galería de figuras - inédita en el teatro peninsular - exige el movimiento de sus cuerpos: el Parvo o el Diablo requieren de sus actores una gesticulación más visible y un mayor dinamismo en escena. El Fraile, por otro lado, se acerca a la especialización actoral pues, aunque resulta temprano para ello, el actor que lo encarnara debería saber declamar, cantar y bailar. Además de sus diálogos, el Diablo le pide que realice el «tordião»,

36 "Adverbio latine longe, de donde se derivó; es opuesto a la palabra cerca. De aquí se deriva el verbo alejar. En la pintura llamamos lejos lo que está pintado en disminución, y representa a la vista estar apartado de la figura principal [...]» 
que es un "baile cantando o el "canto que acompanhava esse baile»37 y, finalmente, se atreve a dar una lección de esgrima en un pasaje muy sugerente y descriptivo para demostrar su condición cortesana. Por ello nos inclinamos a pensar que el papel es demasiado completo para que no lo realizase un actor con cierta experiencia, pues el Fraile no solo se dedica a mostrar con gracia el arte de la esgrima, sino que también debe decir un texto bastante amplio que incluye situaciones graciosas.

A partir de aquí, pueden lanzarse dos hipótesis: o bien Gil Vicente aprovechó la destreza con la espada de un actor de los que disponía - o su capacidad imitativa - , o bien el papel fue representado por un miembro de la Corte con dicha habilidad, que se convirtió en actor para la ocasión. Ambos casos son plausibles y llegar a la verdad del asunto es una quimera, eso sí, resulta muy estimulante pensar que, de cualquier forma, nos hallamos ante un autor que escribe pensando en lo que saben hacer o no los actores - sean estos más o menos profesionales — de los que dispone.

La evolución de la farsa es también notoria, pues desde el temprano Auto da Índia hasta la magistral Farsa de Inês Pereira hay una mayor técnica relacionada, sobre todo, con el ámbito de la voz. Esta última presenta juegos escénicos basados por completo en los apartes, la ironía, la modulación, el canto torpe y el guaiado o el habla de los judíos Latão y Vidal. Pero también la gestualidad es importante en ella, pues los personajes hacen fingimentos, se ponen em feição, actuan con decoro, etc. Es un teatro que, no obstante, se sirve del decir de los actores para hacer avanzar la acción y conferirle la cohesión estructural de que precisa. Así ocurre cada vez que un personaje se dispone a cruzar la puerta de entrada, pues se le da paso o es presentado en los versos inmediatamente anteriores. Esta técnica, ingeniosa y moderna por demás - aunque ya utilizada de forma similar por Encina y Fernández — responde al principio de economía teatral y supone, también, que algunos de los personajes requieren de un refuerzo identificativo mediante la presentación. Pese a que seguramente irían vestidos adecuadamente — según su condición —, se caracterizan, sobre todo, por su comportamiento verbal y gestual.

37 Michaelis Moderno Dicionário da Língua Portuguesa, Melhoramentos Ltda., edición en línea (http://michaelis.uol.com.br/moderno/portugues/). 
Pero uno de los mejores testimonios de la técnica utilizada en las farsas analizadas lo hallamos en el personaje de la criada del Auto da Índia, cuyos comentarios sobre el Ama se realizan en apartes cargados de ironía, en los que se compadece del Marido: «Virtuosa está minha ama! / Do triste dele hei dó» (vv. 55-56). Por su parte, el Ama desconfía de las palabras dichas por su criada, posiblemente, al público y, por ello, le inquiere al respecto: «E que falas tu lá só?» (v. 57). La Moça responde con disimulo: «Falo cá com esta cama» (v. 58). Estos versos funcionan a modo de didascalia implícita para constatar el aparte de la criada. Así, la expresión falar só podría considerarse un sinónimo de aparte al igual que la expresión ando dizendo entre $m i$, utilizada con posterioridad por el mismo personaje:

$$
\begin{gathered}
\text { MoçA Quantas artes quantas manhas } \\
\text { que sabe fazer minha ama: } \\
\text { um na rua outro na cama. } \\
\text { Ama Que falas, que t'arreganhas? } \\
\text { MoçA Ando dizendo entre mi } \\
\text { que agora vai em dous anos } \\
\text { que eu fui lavar os panos } \\
\text { além do Chão d'Alcami. }{ }^{38} \\
\text { (vv. 353-360) }
\end{gathered}
$$

Ambas expresiones implican un cambio en el tono y volumen de la criada al realizar el aparte que despierta el recelo del Ama, que, a su vez, también jugará la baza del disimulo con sus amantes para ocultar a cada uno la existencia del otro. Decir o hablar entre si - al igual que falar só - forma, en nuestra opinión, parte de la técnica del actor del Quinientos.

El juego escénico está servido y las situaciones requieren, como podemos intuir en estos versos, una tejné notablemente desarrollada y alejada de la de las obras de temática religiosa de Vicente, de las cuales se encuentra separada por un espacio de tiempo de tan solo seis o siete años. Los actores

38 Los subrayados son nuestros. 
no serían cortesanos sino amateurs provenientes del teatro callejero o gente al servicio de la corte con habilidades.

En cuanto a las comedias, también hallamos grandes diferencias entre las analizadas, así como una gran riqueza y variedad interpretativa. De hecho, la Comédia de Rubena ya incluye muchos de los topoi que tanto éxito conocerá posteriormente el género y la mezcla del mundo farsesco y del cortesano permite a Vicente hacer pasar por su obra personajes que podrían representarse de diversos modos: el mundo del pecado de Rubena, repleto de personajes histriónicos y grotescos; el mundo de Cismena, que contiene algunos tipos cómicos que no parecen provenir de la misma tradición gestual. Es el caso de las dos criadas (Benita y Clita), pues mientras la primera es maliciosa e irónica y hace un uso constante del aparte similar al de las farsas, la criada de Cismena ama a su señora y se convierte en su coadyuvante incondicional. La primera de ellas debe actuar a lo gracioso, mientras que la segunda, aunque con alguna pincelada cómica, mantiene el tono de gravedad de su señora. Otro hecho destacable lo hallamos en la puesta en escena de los dolores del parto de Rubena, que deberían exigir maquillaje y vestuario adecuado. Los demonios también presentan esta dificultad representativa y parecen exigir el uso de máscaras, pies, rabos... En cuanto a los tipos de la Corte, hemos identificado al Portugués enamorado, la Alcahueta, el Vejete enamorado - perteneciente a la tradición cuentística y futuro Pantalone y su Criado-Bobo (futuro Arlecchino). Personajes de éxito, en definitiva, que pasarán por un teatro castellano posterior a Vicente ya profesional como el de Lope de Rueda, cuajando definitivamente en la Comedia Nueva.

La técnica compositiva de Gil Vicente, creemos, debía estar en consonancia con el arte interpretativo de los cómicos; a estos el texto les plantea cada vez más exigencias — como constata el análisis semántico —, pues al dominio nada despreciable de la tejné vocal y gestual se le añadiría que muchos de ellos debían saber cantar, bailar, etc. El hecho de que algunos personajes aparezcan sin texto y luego canten o bailen también nos conduce a la sospecha de que tal vez fueran especialistas en estos ámbitos.

Finalmente, en las comedias de temática caballeresaca - Dom Duardos y Amadís de Gaula —, Vicente tratará de reflejar una Corte ideal, recreando ya no escenas entre pastores sino entre damas y caballeros. Nuestro 
autor sabe que no puede representar de la misma forma las baxas y las altas figuras y, por ello, acude a otras fuentes de personajes ideales: la materia novelesca, tratados, espejos de príncipes...

Una mirada superficial podría llevarnos hacia el pesimismo, pues en ellas el Mestre Gil parece regresar a un teatro de más palabras y menos acción. Pero esto solo ocurre en apariencia, pues si bien es cierto que el decoro le impide construir de la misma forma los personajes de farsa y los de comedia, también lo es que logra escalar un peldaño más, pues evoluciona no hacia el teatro de palabras ni al de la acción, sino hacia el teatro del personaje. Todo en Dom Duardos está creado para caracterizar a los personajes: la acción es personaje, el paisaje es personaje, la lírica es personaje... La actuación, por tanto, también ha de ser más comprometida, más profunda, menos estereotipada y, por ello, los actores expresan sus miedos e intenciones a través de largos soliloquios. Sus versos encierran dramatismo, conllevan acción, cambio, evolución, y expresiones como disforme visaje, vil figura o paños viles sirven para describir las transformación externa de Dom Duardos en Julián, quien no obstante muestra su verdadero yo al turbarse y mostrarse corrido ante la belleza de Flérida. Preciso adjetivo proveniente de correrse, que según Covarrubias «Vale afrentarse, porque le corre la sangre al rostro. Corrido, el confuso y afrentado. Corrimiento, la tal confusión o vergüença. Andar corrido, andar o afrentado, o trabajado de una parte a otra.»

Por supuesto, esta representación del enamorado es muy distinta al de las farsas y ejemplifica bien que estos nuevos dramas presentan personajes dotados de una mayor profundidad psicológica, dueños de momentos de tensión y gran lirismo que, sin duda, requerirían un actor muy distinto al de las farsas. Un representante con capacidad oratoria y heredero de toda la tejné acumulada a través de la práctica de otros géneros, que debe aparecer transformado en estas obras en un personaje inédito en el tablado cortesano. Tiene a su alcance las propias herramientas con que el autor lo ha dotado a través del texto y la intuición que pueda proporcionarle esa herencia gestual y cultural de que es depositario.

El análisis semántico de las obras nos ofrece, en definitiva, tanta información sobre el actor y su técnica que, a nuestro parecer, surgen ante nosotros tanto un nuevo autor como un actor que no sólo explican las 
posteriores prácticas escénicas, sino que constituyen el comienzo de la profesión. Gil Vicente no es un poeta sino un dramaturgo en constante desarrollo, con plena conciencia de que sus obras se escriben para ser representadas, que construye personajes con un elenco más o menos estable de representantes, a quienes dirige marcando el tono y modo de la representación según las circunstancias de la misma. A falta de seguir transitando este fructuoso camino, se aprecia una fecunda confluencia de tradiciones expresivas e interpretativas que daría paso a una variedad también de actores - de diversas procedencias y más o menos ocasionales-, que levantaron los pilares de algunos de los tipos más desarrollados en el posterior teatro. El mayor o menor detalle de su técnica, su progresión y su verdad habrá de definirse en posteriores y más amplios estudios. 